\title{
Pattern of third molar impaction in a Saudi population
}

\author{
Ali H Hassan' \\ 'Department of Preventive Dental \\ Sciences, Faculty of Dentistry, King \\ Abdulaziz University, Jeddah, \\ Saudi Arabia
}

This article was published in the following Dove Press journal:

Clinical, Cosmetic and Investigational Dentistry

7 October 2010

Number of times this article has been viewed
Objective: To evaluate the current pattern of third molar impaction in a sample of Saudi patients. Methods: One thousand thirty-nine orthopantomograms (OPG) of patients ranging in age from 19 to 46 years (536 males and 503 females) were evaluated to determine the frequency of impacted third molars, their levels of eruption, and their angulations.

Results: Four hundred twenty-two (40.5\%) of the 1039 OPG showed at least one impacted third molar, with no significant difference between males $(222 ; 52.6 \%)$ and females $(200 ; 47.4 \%)$ $(P=0.284)$. The most common number of impacted third molars per OPG was one $(72.5 \%)$. Impacted third molars were 1.64 times more likely to occur in the mandible than in the maxilla. The most common angulation of impaction in the mandible was the mesial (33.4\%), while the most common angulation in the maxilla, was the vertical (49.6\%). Level B impaction was the most common in both maxilla (48.2\%) and mandible (67.7\%). There was no significant difference in the frequency of impaction between the right and left sides in both jaws.

Conclusion: The pattern of third molar impaction in the western region of Saudi Arabia is characterized by a high prevalence of impaction that is greater in the mandibles and with no sex predilection.

Keywords: third molar, impaction, prevalence, Saudi

\section{Introduction}

Tooth impaction is a pathological situation in which a tooth can not, or will not, erupt into its normal functioning position, unless facilitated by treatment. ${ }^{1}$ Etiology of permanent teeth impaction includes several systemic and local factors. Cleidocranial dysplasia, Down syndrome, endocrine deficiencies (hypothyroidism and hypopituitarism), febrile diseases, and irradiation, are some of the systemic factors that may influence impaction of permanent teeth. ${ }^{2,3}$ More commonly, local factors include prolonged deciduous tooth retention, malposed tooth germs, arch-length deficiency, supernumerary teeth, odontogenic tumors abnormal eruption path, and cleft lip and palate. ${ }^{4-6}$

Third molar is the most frequently impacted tooth. ${ }^{7}$ The prevalence of third molar impaction ranges from $16.7 \%$ to $68.6 \% .{ }^{7-16}$ Most studies have reported no sexual predilection in third molar impaction. ${ }^{7,8,11,13,15}$ Some studies, however, have reported a higher frequency in white European females ${ }^{17,18}$ and Singapore Chinese females than males. ${ }^{16}$

Several methods have been used to classify impaction, in which impaction is described based on the level of impaction, ${ }^{19}$ the angulations of the third molars,${ }^{20}$ and the relationship to the anterior border of the ramus of the mandible. ${ }^{19}$

Depth or level of maxillary and mandibular third molars can be classified using the Pell and Gregory classification system, ${ }^{19}$ where the impacted teeth are assessed
Correspondence: Ali H Hassan Department of Preventive Dental Sciences, Faculty of Dentistry, King Abdulaziz University, Jeddah, 21332 Saudi Arabia

Tel +9666401000 ext 22267

Fax+9666403316

Email aakbr@kau.edu.sa 
according to their relationship to the occlusal surface (OS) of the adjacent second molar. If the third molar is at the same level or above the occlusal surface of the adjacent second molar, then it is classified as A. If it is between the OS and the cervical line of the second molar then it is classified as $\mathrm{B}$. $\mathrm{C}$ level is when the third molar is below the cervical line of the adjacent second molar. ${ }^{19}$ Third molars can also be classified according to the relationship between the cemento enamel junction (CEJ) of the impacted tooth and the associated bone level (Table 1) ${ }^{19}$ Level A is assigned to any impacted third molar that is not buried in bone. Level B is assigned to any impacted third molar that is partially buried in bone, when any part of the CEJ is lower then the bone level. Level C is assigned to impacted third molars that are completely buried in bone.

Impacted third molars can also be classified according to their angular relationship to the adjacent second molar. Angulation of the impacted third molar can be determined by evaluating the angle formed between the intersected longitudinal axes of the impacted third molar and the adjacent second molar, as described by Winter, ${ }^{20}$ either visually or by using an orthodontic protractor (Table 2). ${ }^{16}$

In Saudi Arabia, pattern of third molar impaction has not been assessed, except in one study which was conducted in the central region 25 years ago. ${ }^{13}$ Haidar and Shalhoub ${ }^{13}$ evaluated 1000 orthopantomograms (OPGs) and reported an incidence of $32.3 \%$ for third molar impaction with no sex predilection. However, there are no other recent studies about third molar impaction in Saudi Arabia. The objective of this study was to evaluate the pattern of third molar impaction as seen on panoramic radiograph in a sample of patients living in the western region of Saudi Arabia.

\section{Materials and Methods Sample}

This study was approved by the Ethical Research Committee at the Faculty of Dentistry, King Abdulaziz University (KAU-FD), in which records of 1940 adult patients attending KAU-FD, between the years 2005 and 2006, were reviewed. One thousand thirty-nine orthopantomograms (OPG) of

Table I Classification of third molar impaction by level of the impaction

\begin{tabular}{ll}
\hline Level & Definition \\
\hline Level A & $\begin{array}{l}\text { Not buried in bone } \\
\text { Level B }\end{array}$ \\
$\begin{array}{l}\text { Partially buried in bone (if any part of the CEJ was lower } \\
\text { then the bone level) }\end{array}$ \\
Level C & Completely buried in bone \\
\hline
\end{tabular}

Abbreviation: CEJ, cemento-enamel junction.
Table 2 Classification of third molar impaction by angulation

\begin{tabular}{ll}
\hline Level of impaction & $\begin{array}{l}\text { Angulation of third molar } \\
\text { to second molar }\end{array}$ \\
\hline Vertical impaction & $10^{\circ}$ to $-10^{\circ}$ \\
Mesioangular impaction & $11^{\circ}$ to $79^{\circ}$ \\
Horizontal impaction & $80^{\circ}$ to $100^{\circ}$ \\
Distoangular impaction & $-11^{\circ}$ to $-79^{\circ}$ \\
Others & $111^{\circ}$ to $-80^{\circ}$ \\
Buccolingual impaction* & \\
\hline
\end{tabular}

Note: *Any tooth oriented in a buccolingual direction with crown overlapping the roots.

patients aged 19 years and older (536 males and 503 females) and their related data were selected from these records. The remaining 53\% were excluded for one of the following reasons: aged younger than 19 years; a history of any dental extraction; orthodontic treatment or dento alveolar trauma; incomplete root formation of the third molars; any pathological dento alveolar condition; any craniofacial anomaly or syndrome such as Down syndrome; cleidocranial dysostosis; and the presence of incomplete records or poor quality OPG.

\section{Methods}

OPGs were reviewed by a single examiner in a dark room using an appropriate X-ray viewer to determine the prevalence of impacted third molars in the sample, their levels of eruption; and their angulations. Third molar status was determined based on the patient's chart and the OPG. Third molar was considered impacted if it was not in functional occlusion and at the same time, its roots were fully formed. The level of impaction was determined according to the relationship of the CEJ of the third molar relative to the alveolar bone level (Table 1). The angulation was assessed by measuring the angle formed between the long axis of the third molar relative to the long axis of the second molar, using an orthodontic protractor (Table 2).

Data was analyzed using a Pearson chi-square $\left(\chi^{2}\right)$ test, performed using the Statistical Package for the Social Sciences (version 15.0; SPSS, Inc, Chicago, IL). All assessment was done by a single examiner to eliminate inter-examiner errors. One hundred OPGs were reassessed twice, with a two-week interval, to measure intra-examiner error. This was found to be $9.3 \%$.

\section{Results}

The average age of subjects with impacted third molars was $28.11 \pm 7.25$ years (Table 3 ). Of the 1039 OPGs, 422 showed at least one impacted third molar (Table 4), with no significant difference between males (222; 52.6\%) and females $(200 ; 47.4 \%)(P=0.284)$. Accordingly, data of males and females was pooled. The percentage of subjects having impacted third molars was $40.5 \%$. The total number 
Table 3 Age distribution of the sample

\begin{tabular}{llll}
\hline & & Number $(\%)$ & Age (mean \pm SD) \\
\hline Total sample & & $1039(100)$ & $28.1 I(7.25)$ \\
Impaction group & Male & $222(52.6)$ & $26.58(6.60)$ \\
& Female & $200(47.4)$ & $26.77(6.74)$ \\
& Subtotal & $422(40.5)$ & $26.67(6.65)$ \\
Control group & Male & $314(50.9)$ & $29.46(7.63)$ \\
& Female & $303(49.1)$ & $30.1(7.44)$ \\
& Subtotal & $617(59.5)$ & $29.75(7.55)$ \\
\hline
\end{tabular}

Abbreviation: SD, standard deviation.

of impacted third molars was 422 . The most common number of impacted third molars per OPG was one $(72.5 \%)$ and the least common number was four (3.3\%) (Table 5).

The distribution of impacted third molars between the upper and lower jaws was also evaluated (Table 6). The proportion of impacted mandibular third molars (53.1\%) was significantly more than that of impacted maxillary third molars (31.8\%), and more than that of impacted upper and lower third molars together $(15.1 \%)(P=0.000)$. Impacted third molars were 1.64 times more likely to occur in the mandible than in the maxilla.

The most common angulation of impaction in the mandible was the mesial (33.4\%), followed by the horizontal $(27.5 \%)$. The most common angulation of impaction in the maxilla was the vertical $(49.6 \%)$, followed by the distal (25.4\%) (Table 7).

The occurrence of the different levels of impaction is shown in Table 8. Level B impaction was the most common in both maxilla (48.2\%) and mandible (67.7\%) (Table 8 ). There was no significant difference between the right and left sides in both the maxilla $(P=0.259)$ and the mandible $(P=0.363)$ (Table 9).

\section{Discussion}

This is the first study to evaluate the prevalence of third molar impaction in the western region of Saudi Arabia. Unlike other regions of Saudi Arabia, the western region of Saudi Arabia, also known as Hijaz, is unique in its ethnic diversity, which is mainly attributed to the Hajj occasion, where Muslims from all over the world come to attend this yearly Islamic pilgrimage in Makkah. Saudis who live in this region

Table 4 Gender distribution of the impaction group

\begin{tabular}{lllllll}
\hline & Male & Female & Total & Chi-square & df & $\begin{array}{l}\text { Asymp. } \\
\text { sig. (2-tailed) }\end{array}$ \\
\hline Number & 222 & 200 & 422 & 1.147 & I & 0.284 \\
Proportion & $52.6 \%$ & $47.4 \%$ & $100 \%$ & & & \\
\hline
\end{tabular}

Abbreviations: $\mathrm{df}$, degrees of freedom; Asymp. Sig., asymptotic significance.
Table 5 Distribution of third molar impaction by number of impactions

\begin{tabular}{lllll}
\hline No. of impactions & Total (\%) & Chi-square & df & $\begin{array}{l}\text { Asymp. } \\
\text { sig. (2-tailed) }\end{array}$ \\
\hline 1 & $306(72.5)$ & 773.8 & 4 & 0.000 \\
2 & $82(19.4)$ & & & \\
3 & $20(4.8)$ & & & \\
4 & $14(3.3)$ & & & \\
Total & $422(100)$ & & & \\
\hline
\end{tabular}

Abbreviations: df, degrees of freedom; Asymp. Sig., asymptotic significance.

are of mixed ethnic origin and are descendants of Arabs, Indians, Turks, Indonesians, Africans, and others. Most have settled in the western region and eventually became Saudis. ${ }^{21}$

The sample size used was equivalent to the samples used in many other international studies..$^{13,16,22}$ However, our sample is the most recent one. Selection criteria included patients aged older than 19 years, as growth is essentially completed by this age ${ }^{23}$ and many third molars have their roots completed by this time. The other selection criterion (complete root formation of the third molars) was also used to ensure correct judgment of the status of the third molar, whether impacted or not. In addition, all patients having systemic conditions that might cause impaction were eliminated, since the scope of the present study focuses on the status of third molars in healthy people.

In this study, the frequency of impacted third molars in the western region of Saudi Arabia was estimated at $40.5 \%$, which is higher than the prevalence estimated in the central region 25 years ago, which was reported to be $32.3 \% .{ }^{13}$ In addition to the time difference between the two studies, the higher frequency seen in the western region can be attributed to the different ethnic background of the people living in the two regions. The reported prevalence in this study is also higher than that reported by Eliasson et $\mathrm{al}^{24}(30.3 \%)$, Hattab et $\mathrm{al}^{8}(33 \%)$, Monteluis ${ }^{15}(32 \%)$, and Rajasuo et al ${ }^{22}(38 \%)$. On the other hand, it is less than that reported by Morris and Jerman ${ }^{25}$ and Quek et al, ${ }^{16}$ who reported frequencies of $65.6 \%$ in a study of 5000 subjects in USA and $68.6 \%$ in a sample of 1000 subjects in Singapore, respectively.

Table 6 Distribution of impacted teeth by area of the jaw

\begin{tabular}{lllll}
\hline Area of jaw & Number (\%) & Chi-square & df & $\begin{array}{l}\text { Asymp. } \\
\text { sig. (2-tailed) }\end{array}$ \\
\hline Maxillary & $184(31.8)$ & 3.58 & 3 & 0.000 \\
Mandibular & $306(53.1)$ & & & \\
Both & $87(15.1)$ & & & \\
Total & $577(100)$ & & & \\
\hline
\end{tabular}

Abbreviations: $\mathrm{df}$, degrees of freedom; Asymp. Sig., asymptotic significance. 
Table 7 Distribution (\%) of third molar impaction by angulations

\begin{tabular}{lllllllllll}
\hline & M & D & V & H & BL & O & Total & $\chi^{2}$ & $\begin{array}{c}\text { df } \\
\text { Asymp. } \\
\text { sig. (2-tailed) }\end{array}$ \\
\hline Maxillary impacts & 39 & 58 & 113 & 17 & 0 & 1 & 228 & 89.1 & 3 & 0.000 \\
Mandibular impacts & $(I 7.1)$ & $(25.4)$ & $(49.6)$ & $(7.5)$ & $(0)$ & $(0.4)$ & & & & \\
& 117 & 58 & 72 & 96 & 6 & 0 & 349 & 102.1 & 4 & 0.000 \\
Total & $(33.4)$ & $(16.6)$ & $(20.6)$ & $(27.5)$ & $(1.7)$ & $(0)$ & & & & \\
& 156 & 115 & 185 & 114 & 6 & 1 & 577 & 160.2 & 4 & 0.000 \\
\hline
\end{tabular}

Abbreviations: M, mesioangular; D, distoangular; V, vertical; H, horizontal; BL, buccolingual; O, others; $\chi^{2}$, chi-square; df, degrees of freedom; Asymp. Sig., asymptotic significance.

No sex predilection was found in this study, which agrees with the majority of the international studies about third molar impaction, such as those performed by Montelius, ${ }^{15}$ Aitasalo et al, ${ }^{26}$ Brown et al, ${ }^{11}$ Dachi and Howell, ${ }^{7}$ Haidar and Shalhoub, ${ }^{13}$ Hattab et al, ${ }^{8}$ Kramer and Williams, ${ }^{14}$ and Morris and Jerman. ${ }^{25}$ However, it disagrees with a few other studies, such as those of Hellman, ${ }^{27}$ Hugoson and Kugelberg, ${ }^{17}$ Murtomaa et al, ${ }^{18}$ and Quek et a ${ }^{16}$ who reported a higher frequency of third molar impactions among females. The higher frequency reported in females was explained as a consequence of the difference between the growth of males and females. Females usually stop growing when the third molars just begin to erupt, whereas in males, the growth of the jaws continues during the time of eruption of the third molars, creating more space for third molar eruption. ${ }^{16,27}$ However, the majority of international studies show no sex predilection.

The current study is in agreement with those of Quek et al, ${ }^{16}$ Kramer and Williams, ${ }^{14}$ and Moris and Jerman ${ }^{25}$ regarding the most common angulation in the mandible, which was the mesioangular (33.5\%). However, the findings are in contrast to those of Hugoson and Kugelberg, ${ }^{17}$ who found the vertical angulation to be the most common. This could be due to the fact that a different method of classification of angulation was used in this study. In the present study, the most common angulation registered in the maxilla was the vertical angulation and this is in agreement with Quek et al. ${ }^{16}$ However, it disagrees with Kruger et $\mathrm{al}^{28}$ who found that mesioangular impaction was the most frequently observed pattern of impaction in the maxilla.
Level of impaction was assessed according to the level of CEJ of the third molar relative to the alveolar bone height and not according to the relationship to the occlusal surface of the adjacent second molar. This is more objective since it excludes any normally erupting third molars. The B level was the most common level of impaction in both maxilla (48\%) and mandible $(67.5 \%)$ in this study. This agrees with the findings of Quek et al ${ }^{16}$ but not those of Hugoson and Kugelberg, ${ }^{17}$ who classified the level of the third molar differently, according to the relationship of the third molar to the occlusal surface of the adjacent second molar. They therefore included the erupted third molars in determining the frequency of each level.

The etiology of the third molar impaction has been investigated in many international studies. Several factors were reported as possible causes for third molar impaction: including lack of space distal to the permanent second molar; retarded third molar mineralization; and early physical maturation. ${ }^{29-32}$ Unfortunately, the etiology of third molar impaction has never been investigated in any Saudi population. Future studies are required to evaluate the etiology behind this relatively high frequency of third molar impaction in the western region of Saudi Arabia.

The present study, like most of the previous studies about third molar impaction, used a hospital based sample, which lacks randomization. More precise studies are necessary to evaluate the impaction of third molars in a randomized sample representative of Saudi Arabia. In addition, future studies are required to evaluate the pattern of third molars in the other regions of Saudi Arabia.

Table 8 Distribution (\%) of third molar impaction by level of impaction

\begin{tabular}{|c|c|c|c|c|c|c|c|}
\hline Jaw level & A & B & C & Total & $\chi^{2}$ & df & $\begin{array}{l}\text { Asymp. } \\
\text { sig. (2-tailed) }\end{array}$ \\
\hline \multirow[t]{2}{*}{ Maxilla } & 103 & 110 & $15(6.6)$ & 228 & 75.71 & 2 & 0.000 \\
\hline & $(45.2)$ & $(48.2)$ & & $(100)$ & & & \\
\hline \multirow[t]{2}{*}{ Mandible } & 96 & 235 & $18(4.9)$ & 349 & $2.115 E 2$ & 2 & 0.000 \\
\hline & $(27.5)$ & $(67.7)$ & & $(100)$ & & & \\
\hline \multirow[t]{2}{*}{ Total } & 199 & 346 & 31 (5.4) & 577 & $5.322 \mathrm{E} 2$ & 3 & 0.000 \\
\hline & (34.5) & $(60.1)$ & & $(100)$ & & & \\
\hline
\end{tabular}

Abbreviations: $\chi^{2}$, chi-square; df, degrees of freedom; Asymp. Sig., asymptotic significance. 
Table 9 Distribution (\%) of third molar impaction by side of impaction

\begin{tabular}{lllllll}
\hline & $\begin{array}{l}\text { Right } \\
\text { side }\end{array}$ & $\begin{array}{l}\text { Left } \\
\text { side }\end{array}$ & Total & $\chi^{2}$ & df & $\begin{array}{l}\text { Asymp. } \\
\text { sig. (2-tailed) }\end{array}$ \\
\hline Maxillary & 122 & 106 & 228 & 1.273 & $\mathrm{I}$ & 0.259 \\
& $(53.5)$ & $(46.5)$ & $(100)$ & & & \\
Mandibular & 166 & 183 & 349 & 0.828 & $\mathrm{I}$ & 0.363 \\
& $(47.7)$ & $(52.3)$ & $(100)$ & & & \\
Total & 288 & 289 & 577 & 0.007 & 2 & 0.934 \\
& $(49.8)$ & $(50.2)$ & $(100)$ & & & \\
\hline
\end{tabular}

Abbreviations: $\chi^{2}$, chi-square; df, degrees of freedom; Asymp. Sig., asymptotic significance.

\section{Conclusion}

The pattern of third molar impaction in the present sample is characterized by a high prevalence with no sex predilection. It is higher in the mandible than in the maxilla. The most common angulation was the mesioangular angulation in the mandible, and the vertical angulation in the maxilla. The most common level of impaction was the B level. There was no significant difference between the right and left sides in both jaws. Future studies are required to evaluate the pattern of third molar impaction in other areas of Saudi Arabia.

\section{Disclosure}

The author reports no conflicts of interest in this work.

\section{References}

1. American Association of Oral and Maxillofacial Surgery. Impacted teeth. Oral Health. 1998;88:31-32.

2. Bishara SE. Impacted maxillary canines: a review. Am J Orthod Dentofacial Orthop. 1992;101(2):159-171.

3. Levi O, Regan D. Impaction of maxillary permanent second molars by the third molars. J Paediatr Dent. 1989;5:31-34.

4. Raghoebar GM, Boering G, Vissink A, Stegenga B. Eruption disturbances of permanent molars: a review. J Oral Pathol Med. 1991;20(4):159-166.

5. Jacoby H. The etiology of maxillary canine impaction. Am J Orthod. 1983;84(2):125-132.

6. Moyres RE. Handbook of Orthodontics. 4th ed. Chicago, IL: Year Book Medical Publishers; 1988.

7. Dachi SF, Howell FV. A survey of 3,874 routine full-mouth radiographs. II. A study of impacted teeth. Oral Surg. 1961;14:1165-1169.

8. Hattab FN, Fahmy MS, Rawashedeh MA. Impaction status of third molars in Jordanian students. Oral Surg Oral Med Oral Pathol Radiol Endod. 1995;79(1):24-29.

9. Scherstén E, Lysell L, Rohlin M. Prevalence of impacted third molars in dental students. Swed Dent J. 1989;13(1-2):7-13.

Clinical, Cosmetic and Investigational Dentistry

\section{Publish your work in this journal}

Clinical, Cosmetic and Investigational Dentistry is an international, peer-reviewed, open access, online journal focusing on the latest clinical and experimental research in dentistry with specific emphasis on cosmetic interventions. Innovative developments in dental materials, techniques and devices that improve outcomes and patient satisfac-
10. Pedersen GW. Surgical removal of teeth. In: Pedersen GW, editor. Oral Surgery. Philadelphia, PA: WB Saunders; 1988:47-81.

11. Brown LH, Berkman S, Cohen D, Kaplan AI, Rosenberg M. A radiological study of the frequency and distribution of impacted teeth. J Dent Assoc S Afr. 1982;37(9):627-630.

12. Fanning EA, Moorees CF. A comparison of permanent mandibular molar formation in Australian aborigines and Caucasoids. Arch Oral Biol. 1969;14(9):999-1006.

13. Haidar Z, Shalhoub SY. The incidence of impacted wisdom teeth in a Saudi community. Int J Oral Maxillofac Surg. 1986;15(5):569-571.

14. Kramer RM, Williams AC. The incidence of impacted teeth. Oral Surg Oral Med Oral Pathol. 1970;29(2):237-241.

15. Montelius GA. Impacted teeth: a comparative study of Chinese and Caucasian dentitions. J Dent Res. 1932;12(6):931-938.

16. Quek SL, Tay CK, Tay KH, Toh SL, Lim KC. Pattern of third molar impaction in a Singapore Chinese population: a retrospective radiographic survey. Int J Oral Maxillafac Surg. 2003;32(5):548-552.

17. Hugoson A, Kugelberg CF. The prevalence of third molars in a Swedish population. An epidemiological study. Community Dental Health. 1988;5(2):121-138.

18. Murtomaa H, Turtola I, Ylipaavalniemi P, Rytomaa I. Status of the third molars in the 20- to 21-year-old Finnish university population. J Am Coli Health. 1985;34(3):127-129.

19. Pell GJ, Gregory BT. Impacted mandibular third molars: classification and modified techniques for removal. Dent Digest. 1933;39:330-338.

20. Winter GB. The Principles of Exodontia as Applied to the Impacted Third Molar. St. Louis, MO: American Medical Book Co; 1926.

21. Hassan AH. Cephalometric norms for saudi adults living in the western region of Saudi Arabia. Angle Orthod. 2006;76(1):109-113.

22. Rajasuo A, Murtomaa H, Meurman JH. Comparison of the clinical status of third molars of young men in 1949 and in 1990. Oral Surg Oral Med Oral Pathol. 1993;76(6):694-698.

23. Fielding AF, Douglass AF, Whitley RD. Reasons for early removal of impacted third molars. Clin Prev Dent. 1981;3(6):19-23.

24. Eliasson S, Heimdahl A, Nordenram A. Pathological changes related to long-term impaction of third molars. A radiographic study. Int J Oral Maxillofac Surg. 1989;18(4):210-212.

25. Morris CR, Jerman AC. Panoramic radiographic survey: a study of embedded third molars. J Oral Surg. 1971;29(2):122-125.

26. Aitaslo K, Lehtinen R, Oksala E. An orthopantomographic study of prevalence of impacted teeth. Int J Oral Surg. 1972;1(3):117-120.

27. Hellman M. Our third molar teeth: their eruption, presence and absence. Dental Cosmos. 1936;78:750-762.

28. Kruger E, Thomson WM, Konthasinghe P. Third molar outcomes from age 18 to 26: findings from a population-based New Zealand longitudinal study. Oral Surg Oral Med Oral Pathol Oral Radiol Endod. 2001;92(2):150-155.

29. Björk A, Jensen E, Palling M. Mandibular growth and third molar impaction. Acta Odont Scand. 1956;14:231-272.

30. Ricketts RM. The principle of arcial growth of the mandible. Angle Orthod. 1972;42(4):368-386.

31. Breik $\mathrm{O}$, Grubor $\mathrm{D}$. The incidence of mandibular third molar impactions in different skeletal face types. Aust Dent J. 2008;53(4):320-324

32. Richardson ME. The etiology and prediction of mandibular third molar impaction. Angle Orthod. 1977;47(3):165-172.

tion and preference will be highlighted. The manuscript management system is completely online and includes a very quick and fair peerreview system, which is all easy to use. Visit http://www.dovepress. com/testimonials.php to read real quotes from published authors. 